\title{
The Assessment of Quality of Products Called Sandalwood Oil Based on the Information Provided by Manufacturer of the Oil on Polish, German, and English Websites
}

\author{
Magdalena Hartman-Petrycka $(i D)$ and Agata Lebiedowska $(\mathbb{D}$ \\ Department of Basic Biomedical Science, Faculty of Pharmaceutical Sciences in Sosnowiec, Medical University of Silesia, \\ Kasztanowa 3, Sosnowiec 41-205, Katowice, Poland \\ Correspondence should be addressed to Agata Lebiedowska; alebiedowska@sum.edu.pl
}

Received 29 March 2021; Revised 29 June 2021; Accepted 3 July 2021; Published 13 July 2021

Academic Editor: Daniela Rigano

Copyright ( $) 2021$ Magdalena Hartman-Petrycka and Agata Lebiedowska. This is an open access article distributed under the Creative Commons Attribution License, which permits unrestricted use, distribution, and reproduction in any medium, provided the original work is properly cited.

Background. Sandalwood oil is one of the most valuable raw materials worldwide. As a highly valued product, it has its own regulations based on the ISO 3518 standard, which clearly informs producers, distributors, and consumers of the requirements to be met. The aim of this study was to assess the quality of products called sandalwood oil based on the information provided by the manufacturer of the oils on Polish, German, and English websites. Methods. A Google search was utilized to collect data on sandalwood oil offered by producers and distributors in Polish and foreign markets. Information from 50 websites in each of the aforementioned languages, including the description of sandalwood oil properties on websites, method for using it, safety limitations, and presence of a product description consistent with the INCI recommendations, was gathered using Microsoft Excel software and was analyzed. The information that enabled us to estimate the quality of the oils was the botanical name of the oilbearing plant and the price. Good-quality oils were considered to be oils with the botanical name Santalum album in the description and with a price not considerably less than the price of white sandalwood oils sold by reliable distributors who control the quality of the oils by chromatography. Ultimately, the lower price limit for one milliliter of the oil was established as PLN 21. Results and Conclusions. Good-quality sandalwood oils derived from the Santalum album plant at a price equal to or greater than the chromatographically tested items amounted to a negligible percentage of products sold online. Without knowing the botanical name of the essential oil plant and the price range of unadulterated sandalwood oil, the likelihood of buying a reliable product is low on all of the analyzed websites, with the lowest probability being observed on the Polish websites.

\section{Background}

The lockdown related to the COVID-19 pandemic has spread across the globe. As people have been confined to their homes, they have transferred their lives to the Internet, and many new instructional videos about performing beauty treatments and making natural cosmetics have appeared. The necessary products have been purchased mainly via the Internet. Although the restrictions related to the COVID-19 pandemic have decreased, interest in online shopping continues to grow [1].

Sandalwood oil is one of the most valuable raw materials and is widely used in cosmetics and natural medicine, showing a number of positive effects on the skin and the entire body. The essential oil obtained from East Indian sandalwood, also known as sandalwood (Santalum album L.) $[2,3]$, is considered to be authentic sandalwood oil. The sandalwood is one of the most valuable trees in the world [3]. The raw materials from this tree were used thousands of years ago in India [2], where it can still be found in the wild, as well as in Indonesia, China, and the Malay Archipelago [4].

Essential oils are substances derived from plants that are under many different legal regulations ensuring their appropriate quality, such as the ISO 9235 standard (Aromatic natural raw materials-vocabulary). ISO standards specify 
the method for obtaining oils, the need to use the term "essential" in the name of the product, and the requirement to inform consumers about the country of origin of raw materials [5]. Sandalwood oil, as a highly valued product, has its own regulations based on the ISO 3518 standard, which clearly informs producers, distributors, and consumers concerning the requirements to be met [6]. Sandalwood oil is produced in the process of distillation only of the scleroderma and the roots of Santalum album L. Sandalwood oil is a transparent raw material that is slightly viscous, slightly yellow, and almost colorless. This material is characterized by a persistent, woody, and sweet fragrance, which is described as "oriental." An important property described in ISO 3518 is the content of free alcohols, which should reach 90\% (Z- $\alpha$-santalol from 41 to $55 \%$ and $Z$ - $\beta$-santalol from 16 to $24 \%)[2,6]$. The high value of sandalwood oil in aromatherapy is additionally achieved by the content of more than 125 ingredients, including other forms of santalol: bergamotol, lanceol, and santalenes $[7,8]$.

Sandalwood oil has a special value in perfumery, and its use guarantees not only an oriental, woody scent but also enhances and preserves the aromatic properties of other fragrance ingredients. It is popular to combine this oil with floral fragrance note oils, such as rose or lavender $[3,9]$. Sandalwood oil is expensive; in Poland, $1 \mathrm{~mL}$ costs more than 20 PLNs; for comparison, citrus essential oils cost approximately $1.2 \mathrm{PLN}$ for $1 \mathrm{~mL}$. The high price is related to the difficulty of obtaining this material caused by previous excessive exploitation, not the lack of raw material efficiency $[9,10]$. The price prompts many perfume and cosmetic manufacturers to look for synthetic or natural substitutes for sandalwood oil. The original, despite its high value, remains an irreplaceable ingredient in many noble fragrance compositions [3, 9].

In traditional medicine, which dates back to the heyday of Ayurveda and ancient China, sandalwood oil has been used as an antidepressant, sedative, and antiseptic [3, 4, 7, 9]. In natural medicine, it is recommended to use sandalwood oil for colds and inflammation of the mouth, bronchi, or urinary tract [3].

Modern medicine has confirmed the ability of sandalwood oil to inhibit inflammatory reactions and deactivate free radicals. Sandalwood oil is an inhibitor of 5-lipoxygenase, and it also reduces the expression of interleukin $1 \mathrm{~b}$ in keratinocytes [7]. Sandalwood oil has an antibacterial effect and develops antibiotic resistance, for example, in Staphylococcus aureus resistant to methicillin [7]. From a dermatology perspective, the effect of sandalwood oil against bacteria, such as Propionibacterium acnes, Staphylococcus epidermidis or Streptococcus pyogenes, which are involved in the etiopathogenesis of many skin diseases, is very important $[6,11-13]$. Its effectiveness against fungi such as Microsporum, Trichophyton, and Epidermophyton, as well as yeasts of the genus Candida, has also been shown, enabling its use in the treatment of mycoses and yeasts. Sandalwood oil is also active against the herpes simplex viruses HSV 1 and HSV 2 [7]. In dermatology, sandalwood oil is also used in psoriasis or atopic dermatitis treatments $[14,15]$. Studies exploring the effect of sandalwood oil inhalation on hay fever have confirmed its positive reaction with the nasal mucosa and the reduction of the severity of allergies [16]. Synthetic ingredients, analogous to those contained in sandalwood oil called "sandaroles," promote wound regeneration and reduce the visibility of scars. Long-term exposure to this substance has a positive effect on the proliferation and migration of keratinocytes, which are favorable to renewal of the epidermis [17].

Numerous studies have indicated the anticarcinogenic effects of sandalwood oil or its main components on urinary bladder, oral cavity and prostate cancers [7]. The ability to induce autophagy and apoptosis in keratinocytes indicates their possible action in preventing the formation of precancerous skin conditions, as well as their transformation into skin cancers [7]. The activation of early antigens against Epstein-Barr virus is also considered to be an anticancer effect of the oil [18]. The anticancer effect of sandalwood oil or its components in breast cancer has been reported, both in animal studies in which the number and size of tumors decreased [19] and in MCF-7 and MCF-10A breast cancer cell lines in which the double strands of DNA were broken [20]. In clinical trials, a cream containing sandalwood oil and turmeric has been shown to reduce the formation of radiation dermatitis in women exposed to radiation as part of breast cancer treatment [21].

The use of sandalwood oil in aromatherapy to relieve stress, symptoms of depression, and insomnia is popular [22]. Studies conducted in mice have shown the calming effect of $\alpha$-santalol on the nervous system through pharmacological transfer evidenced by the flow of this component to the brain [23]. The antidepressant effect of sandalwood oil is related to the direct stimulation of the pineal gland after inhalation, resulting in the release of serotonin [24]. The influence of santalol on insomnia and shortening the time to wake up suggests the possibility of using sandalwood oil for inhalation in elderly individuals with dementia [25].

Consuming sandalwood oil is not a popular method of using it. However, this material is used in food production, in which it mainly serves as an ingredient that gives food the desired taste, and it is regulated by the Food and Drug Administration (FDA) and the European Council [3]. Animal studies have shown that the oral administration of sandalwood oil lowers free blood glucose and levels of total cholesterol, LDL, and triglycerides and shows a supportive effect in the treatment of systemic diseases, such as diabetes [26].

The widely described properties of sandalwood oil occur only in products with an appropriate quality composition. The average consumer cannot verify it by, for example, using chromatography and therefore relies only on the information provided by the manufacturer, which can be found on packaging or the distributor's website.

\section{Objective}

The aim of the study was to assess the quality of products called sandalwood oil based on the information provided by the manufacturer of the oil on Polish, German, and English 
websites. Complementary goals of the study include the investigation of descriptions of sandalwood oil properties, the methods of its use and safety limitations, and the analysis of product description consistent with the recommendations of the International Nomenclature of Cosmetic Ingredients (INCI).

\section{Methods}

A Google search was used to collect data on sandalwood oil offered by producers and distributors on the Polish and foreign markets. The search settings were adjusted depending on the phrase used; that is, when analyzing the Polish-language websites, the search tools were set to "Poland"; on the German-speaking market, they were set to "Germany"; and on the English-speaking market, they were set to "United States" to obtain the most reliable results.

The key phrases that were used to gather information for analysis were "olejek sandałowy" (Polish), "sandelholzöl" (German), and "sandalwood oil" (English). Information from 50 websites in each of the aforementioned languages was analyzed. The content of websites was analyzed according to the search order, excluding positioned pages.

Only the search results that led directly to the website of a product offered by the distributor and not to the home page of the store or company were analyzed. Only the products that had a price specified and might have been purchased were considered. If the product was offered in several different volumes/weights, the smallest available version of the product size was considered.

Information on the description of sandalwood oil properties on websites, method for using it, safety limitations, and presence of a product description consistent with the INCI recommendations was gathered using Microsoft Excel software. The information that enabled us to estimate the quality of the oils was the botanical name of the oilbearing plant and the price. Good-quality oils were considered to be oils with the botanical name Santalum album in the description and with a price not considerably less than the price of white sandalwood oils sold by reliable distributors, who control the quality of the oils by chromatography. Ultimately, the lower price limit for one milliliter of oil was established as PLN 21.

\section{Results}

The largest percentage of websites that provided a description of sandalwood oil properties were in English (98\%), while Polish websites provided such information in $96 \%$ of cases. The lowest percentage of the sandalwood oil property description, presented only on $66 \%$ pages, was provided by the German market.

Fifty-six percent of English websites mentioned certain safety rules when using sandalwood oil. On Polish websites, the results considering the same issue decreased to $38 \%$. The smallest percentage of pages with information about the safety limitations of sandalwood oil was recorded for the German market (18\%).
On the Polish websites, the full product composition consistent with the INCI recommendations was presented on $46 \%$ of websites; on the English market, it was presented on $28 \%$ of websites, and on the German market, it was presented on only $14 \%$ of websites.

According to the criteria established for this study, essential oils can be considered of a good quality only for $8 \%$ of the products on Polish websites compared with $32 \%$ for German websites and 38\% for English websites (Figure 1).

Among oil-bearing plants other than Santalum album, from which oil under the name of sandalwood oil is obtained, West Indian sandalwood Amyris balsamifera is dominant, especially on the Polish market, constituting $54 \%$ of the products (Figure 2). The widespread presence of this material is also notable on German websites (30\%). The English online market is different; Amyris balsamifera oils were sold on only $2 \%$ of websites, but there are oils from other sandalwood species: Santalum spicatum (10\%), Santalum australedonicum (2\%), and Santalum paniculatum (4\%) (Figure 2).

The smallest percentage of products with the botanical name Santalum album included in the description, the price of which was too low, considering the cost of producing sandalwood oil, is notable on the websites in German (4\%). Ten percent of this type of product was found on both Polish and English websites.

The average price for $1 \mathrm{~mL}$ of sandalwood oils under the botanical name Santalum album, which can be considered reliable according to the criteria for this study, was the lowest on websites in Polish at PLN 28.19 and the highest on websites in English at PLN 50.79. On websites in German, the average price per milliliter of oil was PLN 45.35. A similar dependence is also notable for products that cost less than PLN 21/mL, even though the botanical name Santalum album is declared by the producers. Among these products, the average price is also significantly higher for oils sold on English websites, that is, PLN $11.25 / \mathrm{mL}$, compared with the Polish and German online markets, where the values are comparable: PLN 7.36/mL and PLN 7.60/mL, respectively.

A frequent reason for not considering a given product as good-quality sandalwood oil is the lack of a botanical name on the distributor's website, which is especially notable on German websites (26\% of products).

Blends of oils in vegetable oil with the described composition are most often observed on English-language websites (10\%), and a product described as synthetic oil was also observed there. One Polish website was selling oil, the description of which contained contradictory information regarding the oil-bearing plant. In the photo of the oil packaging, there was a different botanical name than in the text describing the oil properties. Well-described mixtures appeared on $6 \%$ of Polish websites.

The purchase of oil from a given website is affected by the position of the website. On websites in Polish, the first three oils meeting the quality criteria were in the 10th, 12th, and 14th positions, respectively, on the list of searched websites; on the German websites, the first three good-quality oils were in the 1st, 3rd, and 4th positions, respectively; on English websites, they were in the $2 \mathrm{nd}$, 6 th, and 7 th positions, respectively (Table 1). 


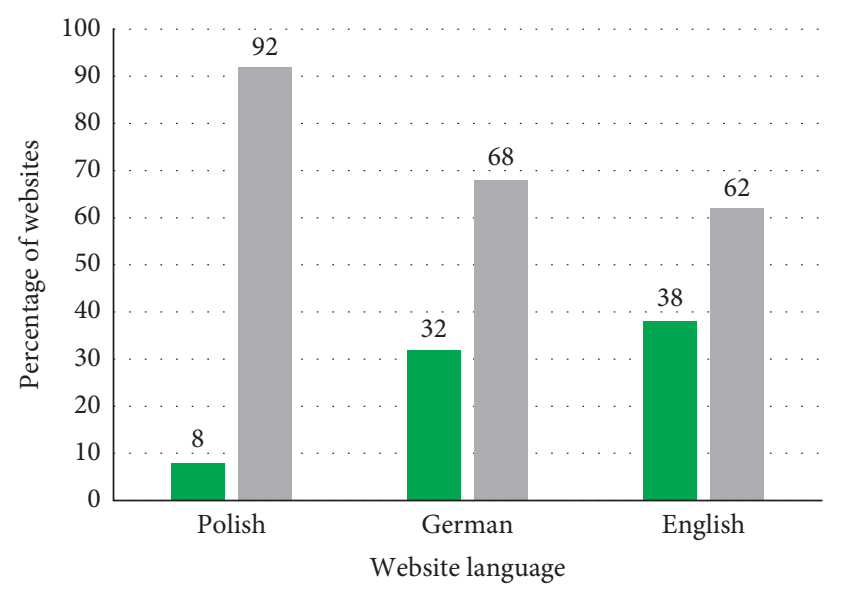

- Good quality

- Bad or unknown quality

Figure 1: Percentage of good-quality oils available on websites in Polish, German, and English.

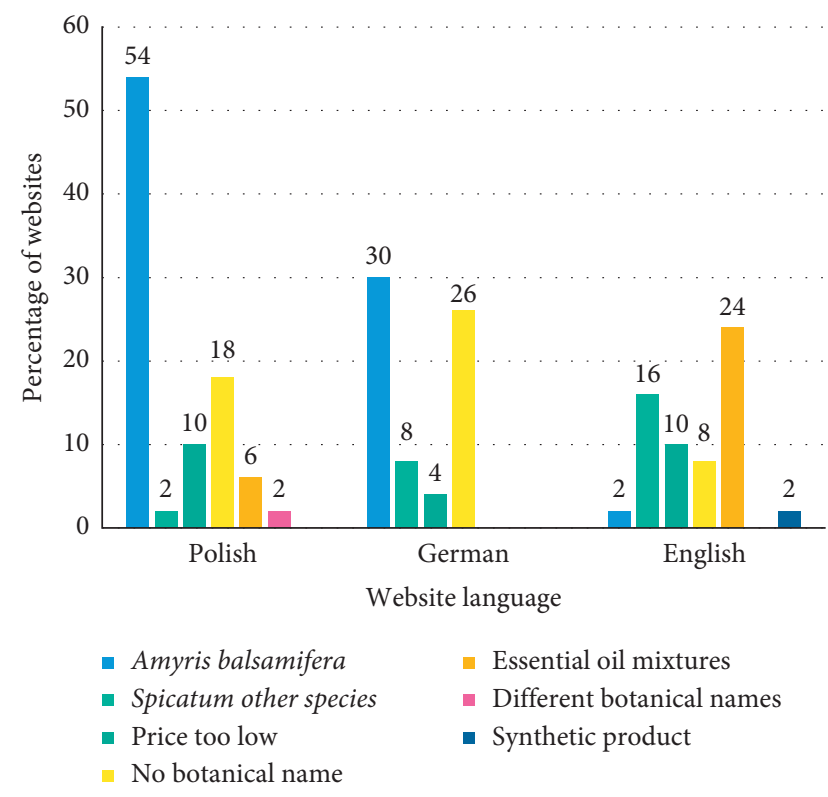

Figure 2: Reasons for qualifying the products as bad-quality oils.

\section{Discussion}

Sandalwood oil is widely used and can be used in natural medicine, especially in aromatherapy. Moreover, modern science has demonstrated the benefits of its application in dermatology, cosmetology, and even oncology [27]. Sandalwood oil can be used by professionals but also commonly, without specialist preparation, for example, in saunas or for air aromatization. Essential oil sellers should provide a goodquality product and basic information for safe use. However, sandalwood oil sellers have not lived up to the challenge in regard to the quality and product description. Each of the analyzed online markets had serious shortcomings, although the authors evaluated the Polish market as the worst with only $8 \%$ trustworthy products and the English market as the best (38\% trustworthy products).
Websites that distribute substances called "sandalwood oil," mostly English and Polish, describe the oils' properties. In the German-speaking market, this description was observed considerably less frequently and covered only $66 \%$ of pages. This study did not undertake a detailed assessment of the information about sandalwood oil on websites, but a cursory analysis indicated that most of them described antidepressant, sedative, and antiseptic properties, which have been known in natural medicine for centuries $[3,4,7,9]$. This phenomenon is undoubtedly beneficial; it allows us to know the richness of the oil for those who are recently acquainted with aromatherapy. Such a description can also inspire deeper knowledge and result in more reliable studies than essential oil seller websites.

The use of essential oils is associated with the risk of allergic reactions, irritation, or photosensitization, especially if they are used incorrectly, for example, in undiluted form [10]. Despite the relatively strong effect of sandalwood oil, which is related to its rich composition, only a small proportion of Polish and German websites contained a safety rule description of the use of this product. Most pages did not even mention the necessity of diluting the essential oil, which is a basic principle of aromatherapy [28]. The assumed criterion, the specification of safety limitations for sandalwood oil use, was met to the greatest extent by English websites (56\%), suggesting that English distributors are most aware of the risks associated with inappropriate use of this oil. This dependency might also be related to stricter laws in English-speaking countries, especially the United States, in terms of the producer's responsibility for the safety of its product.

All cosmetic products, which also include sandalwood oil, should have a description consistent with the International Nomenclature of Cosmetics Ingredients (INCI) guidelines. According to these guidelines, the chemical composition of each product should be described in English. The description should start with the ingredient found in the largest amount in the product. If the product is of plant origin, the Latin botanical name of the plant must be provided [29]. The website analysis showed that the sandalwood oil distributors did not undertake the necessary effort to properly describe the product. The full description compatible with the INCI guidelines appeared only on $45 \%$ of Polish and 14\% of German websites. Perhaps the leaflets attached to the product indicated the full composition in accordance with the INCI guidelines, but distributors, while emphasizing advertising, did not devote proper attention to this aspect, which could contribute to increasing disinformation on the aromatherapy market, both in Poland and abroad.

When examining the differences in the descriptions of the products depending on the language of the website, the historical and cultural aspects in Polish-, German-, and English-speaking countries are worth mentioning. The history of aromatherapy development in Poland is shorter than that in our Western neighbors [30-32]. Aromatherapy has developed differently over the years in Poland and Western countries. The use of essential oils, which is now called aromatherapy, was introduced to modern Europe by 
TABLE 1: Good-quality oil (gray area) or the reason for excluding the oil as good quality in the first, second, and third positions from the top on the list of searched websites in Polish, German, and English.

\begin{tabular}{lccc}
\hline Website position & & Website language & \\
& Polish & German & English \\
\hline 1 & Too low price & Good-quality oil & No botanical name \\
3 & No botanical name & Amyris balsamifera & Good-quality oil \\
\hline
\end{tabular}

the French chemist Rene Gattefosse in 1920 due to the use of lavender oil to help heal wounds. In the literature, this method was described by this researcher for the first time in a book published in 1937. Another French scientist, Dr. Jean Valnet, whose book was published in 1964, is responsible for the development of aromatherapy in Germany. Essential oils also gained popularity quite early in the United Kingdom, which had colonies in India, the homeland of sandalwood oil. The United Kingdom, due to notable participation in exports, also contributed to the spread of aromatherapy in the United States and Australia [30,33]. In Poland, the real development of aromatherapy was initiated by PollenaAroma, along with the potpourri product introduction in 1989. The most important event for aromatherapy in Poland was the publication of the first textbook in Polish on the use of essential oils, Pachnaca Apteka-Tajemnice Aromaterapii, in 1992, 55 years after Rene Gattefosse's publication [31].

Notably, medicine and natural cosmetics are an increasingly popular subject for the average consumer [34], and this popularity does not always go hand in hand with thorough knowledge. A consumer buying a product called sandalwood oil does not always have an idea that he or she might be manipulated and, at the same time, does not have the information that enables him or her to distinguish between genuine and adulterated essential oil. For example, the lack of awareness from which plant sandalwood oil should be obtained creates the risk of unknowingly using products that do not offer the properties expected by the consumer, while a very common trick of essential oil sellers is selling oil from a plant other than Santalum album. In Poland, the situation can be considered scandalous in this aspect. Every second essential oil sold via Polish websites under the name "sandalwood oil" actually comes from the Amyris balsamifera plant, belonging to the Rutaceae (citrus) family. On German websites, the situation is only slightly better; $30 \%$ of websites offered oil from the same plant. Amyris balsamifera is a small tree growing in Haiti and Jamaica [2]. Although this plant is called West Indian sandalwood in Polish, botanically, it has nothing in common with the sandalwood family. The oil obtained from the Amyris balsamifera plant differs in chemical composition from sandalwood oil and thus in its effect on the body. The oil from the Amyris balsamifera plant has become a very popular and less expensive alternative to actual sandalwood oil due to its characteristic woody fragrance, similar to that of sandalwood oil. However, this material cannot be used as a substitute for sandalwood oil in aromatherapy [2]. According to the authors, each oil from the Amyris balsamifera plant should be sold under its own name, for example, as amyris essential oil. Information about the scent notes and possible similarities to sandalwood oil can only be added as supplemental information. The English market is more honest in this regard: the Amyris balsamifera plant only appeared in the description on one English page. In contrast, the English market has the most oils from other sandalwood species compared with the German and Polish markets: Santalum spicatum (10\%), Santalum paniculatum (4\%) and Santalum australedonicum (2\%).

Santalum spicatum comes mainly from southwestern Australia. This species is similar to Santalum album morphologically and physiologically. In contrast to white sandalwood, which is very expensive, sandalwood from Australia could have been used on a considerably larger scale in the nineteenth century due to its abundant occurrence in the natural environment. The oil obtained from Santalum spicatum differs from real Santalum album sandalwood oil, but it gained great popularity in perfumery and aromatherapy at the end of the twentieth century [24]. The essential oil from the Santalum spicatum tree differs in composition from the oil from Santalum album. The most important difference is the content of $\alpha$-santalol and $\beta$-santalol, which in Santalum spicatum is significantly lower. The oil obtained from S. spicatum contains several other substances that increase the fragrance intensity, including farnesol, which occurs in trace amounts in white sandalwood [24]. Due to the differences in composition, Santalum spicatum oil has a slightly different effect than Santalum album oil. The component $\mathrm{E}$, E-farnesol, which is unique to this particular oil, additionally has a sedative effect and can reduce the reaction to mental stimuli, for example, those caused by stimulant consumption. The same ingredient also enhances the effects of other disinfectants. Another ingredient not found in sandalwood oil is epi-alpha-bisabolol, which has an additional anti-inflammatory effect. The beneficial effect of Santalum spicatum oil in preventing the development of atherosclerosis has also been shown [24]. Australian sandalwood oil is considered less safe to use than Santalum album oil due to the high content of farnesol, which is considered a contact allergen [13]. The safety of white sandalwood oil was confirmed by a study in which only $0.1-2.4 \%$ of respondents showed hypersensitivity [7].

Santalum paniculatum is endemic only to Hawaii's largest island, the "Big Island." This tree is the only Hawaiian sandalwood species currently commercially bred but in very limited quantities. Hawaiian sandalwood oil is rare and only sporadically available; it is characterized by a low content of $Z \beta$-santalol and high contents of $\alpha$-santalum, E- $\beta$-santalol, and spirosantalol [35]. 
Santalum austrocaledonicum is less important in modern aromatherapy due to the small-scale production of the essential oil. This species of sandalwood can be found only in New Caledonia and the Republic of Vanuatu [4]. Santalum austrocaledonicum oil met the content of $\alpha$ - and $\beta$-santalol specified by ISO standards for sandalwood oil in only $19 \%$ of the studied trees from two islands of the Republic of Vanuatu [36].

The distinguishing feature of the English Internet market is the relatively frequent (24\%) cases of Santalum essential oils dissolved in vegetable oils in the form of a ready-to-use product, which is not found on the German market at all and rarely found on the Polish market. Such a mixture often includes other essential oils or ingredients, such as vitamin E. This type of product is usually sold in larger packages in plastic bottles of various colors and shapes, while most essential oils are usually sold in 5, 10, and $15 \mathrm{~mL}$ dark glass bottles. In addition, the composition of such blends is described in detail, and it is difficult to mistake them for sandalwood essential oil from Santalum album, although the name "Sandalwood Essential Oil" sometimes appears in the photo, which should not happen.

A separate problem is the complete lack of the botanical name of the oil-bearing plant, both in the product photo and the description. Generally, German websites with poor descriptions (26\% of websites) lead in this regard followed by Polish websites (18\% of websites). Perhaps producers sell good-quality oil but with incorrect descriptions, but considering the overall view of the sandalwood oil market and the level of irregularities, the authors do not recommend buying sandalwood oil from such websites because one cannot tell what one will receive.

Unfortunately, not all websites that have listed the botanical name of the oil plant Santalum album can be trusted due to the price of the product. Good-quality sandalwood oil cannot be too inexpensive. Santalum album was a manifestation of the economy of plunder and excessive exploitation of natural resources for a long time. The most significant amount of oil is obtained from plants more than 30 years old. There was a deficiency of sandalwood oil on the market, which increased its price $[2,9,10]$. Polish companies selling real sandalwood oil checked by the chromatography method offered their product a minimum price of PLN 21 per $1 \mathrm{~mL}$ of oil, and the average price for oils considered by authors as good quality was PLN 28.19 per $1 \mathrm{~mL}$. At the same time, on one of the seemingly reliable Polish websites with a full description containing the botanical name of Santalum album, one could buy sandalwood oil for an almost tenfold lower cost, notably, for PLN 2.64 per $1 \mathrm{~mL}$. The authors considered this price an attempt to fraud and added the price criterion to the selection of good-quality products. When analyzing the prices of oils with the inscribed botanical name Santalum album, regardless of the language, their stratification can be observed. There are expensive and inexpensive products, and there are only a few products with an intermediate price, so the limit of PLN 21 adopted on the Polish market was also used on the German and English markets. The average prices for good-quality oils on these two markets were PLN 45.35 and PLN 50.79 per $\mathrm{mL}$ of product, respectively. The discrepancy in the average price of good-quality products depends on the economic conditions in a region, and the analysis of this issue is beyond the scope of this paper. However, to observe economic inequalities in the described markets, it is worth quoting the average annual salary: Poland $=\$ 31,970 ;$ Germany $=\$$ 53,638; United States $=\$ 65,836$ [37]. Perhaps the annual salary affects the percentage of high-quality sandalwood oils available online, which is $8 \%$ on Polish websites, $32 \%$ on German websites, and $38 \%$ on English websites.

The chance of buying good-quality sandalwood oil on Polish websites is also low because the real oil is not observed until the 10th position on displayed pages on Google, and it is difficult to imagine that an average buyer would visit 10 pages in search of sandalwood oil! The German and English markets are notably better in this respect, and good-quality sandalwood oils can be found on the first three websites.

The authors are aware of several limitations to this study and factors that might have influenced the results.

A significant factor determining the results of the work is the sandalwood oil quality criterion: the presence of the botanical name Santalum album in the product image and/ or on the website and an item price of not less than PLN 21 per $\mathrm{mL}$. In both cases, the results could have been distorted. Some of the oils without the botanical name specified may have actually come from Santalum album, but the distributor did not make an effort to correctly describe the product. The minimum limit of PLN 21/mL was obligatory based on prior knowledge regarding sandalwood oil on the Polish market and the shaping of prices, but perhaps a properly described oil for PLN 17/mL would also turn out to be of good quality after chromatographic examination. For the German and English markets, problems of a different type could arise; the threshold of PLN 21 may have been too low, and good products may have been considered to be of poor quality. There is also the issue of deliberate falsification of the oil, when sellers add less expensive cedar oil but leave a reliable price and the botanical name Santalum album [38].

Another important issue is the method of website searching. The authors made efforts to render this process as objective as possible by, for example, changing the location when changing the search language. However, the working algorithms of Google searches mean that the search history affects subsequent searches; for example, the order of pages might be related to previous searches for various cosmetic products. Having different people perform similar searches on different computers could also lead to differing results.

The most reliable method to assess the quality of sandalwood oil is chromatography. Considering the cost of conducting such research, the authors and online buyers had to rely only on information from sellers and their own knowledge. Despite the limitations of this work and possible inaccuracies in the classification of oils as good or questionable, the observations obtained indicate major shortcomings in the sale of sandalwood oil via the Internet, with the worst results being obtained on Polish websites, convincing the authors to publicize the results.

In Poland, sandalwood oil plays a significant role mainly in perfumery, in which its aromatic qualities are important 
[32]. It can be assumed that, for some consumers, essential oils are only supposed to perform the aroma function, and other aromatherapeutic properties are not as important. Nevertheless, it would be fairer to describe the product in a way in which the potential buyer, even without knowing the botanical name of the oil-bearing plant, would know whether he or she was buying a good-quality product or a less expensive alternative only with similar aromatic qualities. People who buy sandalwood oil for cosmetic or aromatherapy treatments must be particularly careful when buying online and should under no circumstances be guided by the low price.

\section{Conclusions}

Good-quality sandalwood oils derived from the Santalum album plant at a price equal to or greater than the chromatographically tested items amounted to a negligible percentage of products sold online. Without knowing the botanical name of the essential oil plant and the price range of unadulterated sandalwood oil, the likelihood of buying a reliable product is low on all of the analyzed websites, with the lowest probability being observed on Polish sites.

\section{Data Availability}

Data used in this paper are available upon request from the first author.

\section{Disclosure}

This research was performed as part of the employment of the authors at Medical University of Silesia, Katowice, Poland.

\section{Conflicts of Interest}

The authors have no conflicts of interest related to this study.

\section{References}

[1] J. Koch, B. Frommeyer, and G. Schewe, "Online shopping motives during the COVID-19 pandemic-lessons from the crisis," Sustainability, vol. 12, no. 24, p. 10247, 2020.

[2] J. Rhind, Essential Oils a Handbook for Aromatherapy Practice, Singing Dragon, London, UK, 2012.

[3] G. A. Burdock and I. G. Carabin, "Safety assessment of sandalwood oil (santalum album L.)," Food and Chemical Toxicology, vol. 46, no. 2, pp. 421-432, 2008.

[4] A. Ludwiczuk, K. Skalicka-Woźniak, and M. I. Georgiev, Terpenoids, Pharmacognosy, Academic Press, Cambridge, MA, USA, 2017.

[5] International Standard ISO, ISO 9235: Aromatic Natural Raw Materials: Vocabulary, ISO, Geneva, Switzerland, 2013.

[6] International Standard ISO, ISO 3518: Oil of Sandalwood (Santalum Album L.), ISO, Geneva, Switzerland, 2002.

[7] R. L. Moy and C. Levenson, "Sandalwood album oil as a botanical therapeutic in dermatology," The Journal of Clinical and Aesthetic Dermatology, vol. 10, no. 10, pp. 34-39, 2017.

[8] X. Han, C. Beaumont, and N. Stevens, "Chemical composition analysis and in vitro biological activities of ten essential oils in human skin cells," Biochimie Open, vol. 5, pp. 1-7, 2017.
[9] J. Rhind, Fragrance and Wellbeing: An Exploration of Plant Aromatics and Their Influences on the Psyche, Singing Dragon, London, UK, 2014.

[10] W. Brud and I. Konopacka-Brud, "Pachnaca apteka - tajemnice aromaterapii," Oficyna Wydawnicza MA, vol. 35, pp. 126-127, 2008, in Polish.

[11] W. J. Winkelmam, "Aromatherapy, botanicals, and essential oils in acne," Clinics in Dermatology, vol. 36, no. 3, pp. 299-305, 2018.

[12] B. B. Misra and S. Dey, "Comparative phytochemical analysis and antibacterial efficacy of in vitro and in vivo extracts from East Indian sandalwood tree (santalum album L.)," Letters in Applied Microbiology, vol. 55, no. 6, pp. 476-486, 2012.

[13] P. Moretta, R. Cléro, P. Benech, and T. Bader, "Gene expression profile analysis and identification of the effects triggered by essential sandalwood oil on human skin explants," Clinical Dermatology Research Journal, vol. 2, no. 2, 2017.

[14] M. Sharma, C. Levenson, C. Browning et al., "East indian sandalwood oil is a phosphodiesterase inhibitor: a new therapeutic option in the treatment of inflammatory skin disease," Frontiers in Pharmacology, vol. 9, no. 200, 2018.

[15] M. Sharma, C. Levenson, I. Clements, P. Castella, K. Gebauer, and M. Cox, "East indian sandalwood oil (EISO) alleviates inflammatory and proliferative pathologies of psoriasis," Frontiers in Pharmacology, vol. 8, no. 125, 2017.

[16] S. Y. Choi and K. Park, "Effect of inhalation of aromatherapy oil on patients with perennial allergic rhinitis: a randomized controlled trial," Evidence-Based Complementary and Alternative Medicine, vol. 2016, Article ID 7896081, 1 page, 2016.

[17] D. Busse, P. Kudella, N.-M. Gisselmann et al., "A synthetic sandalwood odorant induces wound-healing processes in human keratinocytes via the olfactory receptor OR2AT4," Journal of Investigative Dermatology, vol. 134, no. 11, pp. 2823-2832, 2014.

[18] T. H. Kim, H. Ito, T. Hatano et al., "New antitumor sesquiterpenoids from santalum album of Indian origin," Tetrahedron, vol. 62, no. 29, pp. 6981-6989, 2006.

[19] D. Kaushalkumar, M. A. Fahd, I. Saiful, D. Chandradhar, and P. Omathanu, "Chemoprevention of breast cancer by transdermal delivery of alpha-Santalol through breast skin and mammary papilla (nipple)," Pharmaceutical Research, vol. 34, no. 9, pp. 1897-1907, 2017.

[20] C. Ortiz, L. Morales, M. Sastre, W. E. Haskins, and J. Matta, "Cytotoxicity and genotoxicity assessment of sandalwood essential oil in human breast cell lines MCF-7 and MCF-10a," Evidence-Based Complementary and Alternative Medicine, vol. 2016, Article ID 3696232, 13 pages, 2016.

[21] S. Rao, S. K. Hegde, M. P. Baliga-Rao et al., "Sandalwood oil and turmeric-based cream prevents ionizing radiation-induced dermatitis in breast cancer patients: clinical study," Medicines (Basei), vol. 4, no. 3, 2017.

[22] S. Battaglia, "Essential oil monograph - sandalwood, perfect potion," 2016, https://www.perfectpotion.com.au/news/wpcontent/uploads/2016/04/A4_EssentialOilOfTheWeek_ SANDALWOOD_1304161.pdf.

[23] T. Satou, Y. Ogawa, and K. Koike, "Relationship between emotional behavior in mice and the concentration of (+)- $\alpha$-Santalol in the brain," Phytotherapy Research, vol. 29, no. 8, pp. 1246-1250, 2015.

[24] S. Birkbeck, "The Australian sandalwood oil industry, IFEAT conference-Sydney," 2003, http://pollenaaroma.com.pl/wpcontent/uploads/2015/03/Olejek-sandałowy-z-Australii-art10-02-04.pdf. 
[25] A. Takeda, E. Watanuki, and S. Koyama, "Effects of inhalation aromatherapy on symptoms of sleep disturbance in the elderly with dementia," Evidence-Based Complementary and Alternative Medicine, vol. 2017, Article ID 1902807, 7 pages, 2017.

[26] C. R. Kulkarni, M. M. Joglekar, S. B. Patil, and A. U. Arvindekar, "Antihyperglycemic and antihyperlipidemic effect ofSantalum albumin streptozotocin induced diabetic rats," Pharmaceutical Biology, vol. 50, no. 3, pp. 360-365, 2012.

[27] B. B. Misra and S. Dey, "Biological activities of East Indian sandalwood tree, santalum album," PeerJ PrePrints, p. e96v1, 2013.

[28] J. Lawless, The Encyclopaedia of Essential Oils, Royal Society for the Blind of South Australia, Adelaide, Australia, 1996.

[29] M. V. Heisterberg and T. Menné, "Council Directive 76/768/ EEC of 27 July 1976 on the approximation of the laws of the member states relating to cosmetic products," Official Journal of the European Union, vol. 262, no. 9, pp. 169-200, 2003.

[30] J. Gnatta, L. Kurebayashi, R. Turrini, and M. Paes da Silva, "Aromatherapy and nursing: historical and theoretical conception," Revista da Escola de Enfermagem da USP, vol. 50, 2016.

[31] 25 years of aromatherapy in Poland [25 lat aromaterapii w Polsce]: http://www.drbeta.pl/webpage/25-lat-aromaterapiiw-polsce.html.

[32] J. Góra and J. Gibka, "The most valuable oils - sandalwood oils (oleum Santali albi). [Najcenniejsze olejki - olejek sandałowy (oleum Santali albi)]," Aromatherapy, vol. 4, 1996 in Polish.

[33] K. Urtnowska-Joppek, "Aromatherapy - therapy development at the turn of centuries," Journal of Education, Health and Sport, vol. 8, pp. 1065-1077, 2018.

[34] I. Witczak, "Wybrane problemy zarządzania kapitałem obrotowym netto na podstawie branży kosmetycznej," The Chosen Problems of the Net working Capital Management in the Cosmetic Branch, vol. 17, no. 4, pp. 189-200, 2016.

[35] N. A. Braun, S. Sim, B. Kohlenberg, and B. M. Lawrence, "Hawaiian Sandalwood: oil composition of Santalum paniculatum and comparison with other sandal species," Natural Product Communications, vol. 9, no. 9, 2014.

[36] T. Page, I. Southwell, M. Russell et al., "Geographic and phenotypic variation in heartwood and essential-oil characters in natural populations of Santalum austrocaledonicum in Vanuatu," Chemistry \& Biodiversity, vol. 7, no. 8, pp. 1990-2006, 2010.

[37] Average Annual Wages, Organisation for Economic Co-operation and Development, https://stats.oecd.org/Index.aspx? DataSetCode $=$ AV_AN_WAGE.

[38] L. A. J. Thomson, D. Bush, and M. Lesubula, "Participatory value chain study for yasi sandalwood (Santalum yasi) in Fiji," Australian Forestry, vol. 83, no. 4, pp. 227-237, 2020. 